Revista de Economia Política, vol. 30, $n^{\circ} 4$ (120), pp. 539-559, outubro-dezembro/2010

\title{
Uma mestra na periferia do capitalismo: a economia política de Maria da Conceição Tavares
}

\author{
ROGERIO P. DE ANDRADE \\ RENATA CARVALHO SILVA*
}

\begin{abstract}
A master in the periphery of capitalism. Maria da Conceição Tavares is an eminent figure in Brazilian economic thought, especially in heterodox circles. She has tackled various issues, such as underdevelopment, from the perspective of a "critique of political economy". The purpose of this article is to identify the main theoretical references, as well as the methodological stance, in Tavares's works, by revisiting the author's critical dialogue with some strands of Political Economy. Although Tavares's work sets up a dialogue with various economists, the paper will focus on her interpretation of Marx, Keynes and Kalecki, whose ideas are of utmost importance for the construction of her analytical framework.

Keywords: Maria da Conceição Tavares; Brazilian Economic Thought; Methodology; Marx; Kalecki; Keynes.

JEL Classification: B24; B25; B31; B50.
\end{abstract}

\section{INTRODUÇÃO}

Maria da Conceição Tavares é uma das principais referências no pensamento econômico brasileiro, em particular o de orientação heterodoxa. Embora tenha tratado de vários temas, a problemática do subdesenvolvimento (em especial o caso brasileiro) norteia sua obra. O início de sua trajetória intelectual tem como referência o pensamento da Comissão Econômica para América Latina e Caribe (Cepal) (Tavares, 1963), que procura explicar o atraso das economias periféricas

\footnotetext{
* Respectivamente, Professor do Instituto de Economia, Unicamp. E-mail: roger.andrade@uol.com.br; e Mestranda do Programa de Pós-Graduação em Economia, Universidade Federal Fluminense. E-mail: recarvalho23@gmail.com. Submetido: Janeiro 2009; Aprovado: Agosto 2009.
} 
da América Latina em relação às economias centrais desenvolvidas a partir de uma perspectiva histórico-estrutural.

Ao longo do tempo, Tavares reavaliou alguns aspectos desta matriz teórica, simultaneamente a uma "releitura dos clássicos", introduzindo questões adicionais de grande importância para o entendimento da dinâmica das economias periféricas, como a natureza da acumulação endógena de capital. No caso brasileiro, investigou, por exemplo, as peculiaridades do sistema financeiro do país, geradoras de obstáculos ao desenvolvimento. Tavares tratou também de outros temas, como a natureza da inflação, que nos anos 1980 tornou-se um objeto de estudo central tanto nas economias avançadas, quanto nas periféricas.

A partir de Tavares (1985) é possível identificar um tema adicional em sua agenda de pesquisa. Se antes seu foco de análise recaía sobre as relações centro-periferia, com ênfase sobre o que acontecia na periferia, a partir dos anos 1980 a autora inicia, de forma mais sistemática, reflexões no âmbito da Economia Política Internacional, buscando compreender o caráter hegemônico da economia america$\mathrm{na}^{1}$ e como isso se repercute na periferia, particularmente no Brasil. ${ }^{2}$

É possível, portanto, identificar, na obra de Tavares, três planos de reflexão (de mútua influência): 1) a questão do (sub)desenvolvimento econômico periférico, em particular da economia brasileira; 2) o diálogo crítico com autores importantes da tradição da Economia Política, como Marx, Keynes e Kalecki; 3) a (des)ordem econômica mundial, em que procura lançar uma "visão geopolítica para entender melhor a formação dos centros hegemônicos" (Tavares, 2000, p. 132), tendo como foco da análise a dinâmica das finanças globalizadas. Nesta fase mais recente de sua trajetória intelectual, Tavares buscou fazer "uma releitura do desenvolvimento do sistema capitalista e de seus esquemas de dominação dando ênfase maior ao dinheiro internacional - e não ao progresso técnico - como expressão do nexo de dominação do capital financeiro sobre a periferia", de forma a "reorganizar ao mesmo tempo o conceito de relação entre centro e periferia e o de capitalismo

\footnotetext{
${ }^{1}$ Observe-se que, apesar de uma discussão sobre a hegemonia norte-americana estar mais bem articulada em Tavares (1985), o termo "retomada da hegemonia norte-americana" surge pela primeira vez em Tavares ([1984] 1986, p. 66), publicado, originalmente, no fim de 1984.

${ }^{2}$ A economia política internacional (EPI) é um desdobramento da economia política e possui um caráter interdisciplinar. Seu escopo de análise caracteriza-se pelo seguinte: "The first is the importance of a cross-disciplinary analysis of the global dynamics of modern capitalism, and the critical importance of examining complex and differential power relationships among nations and corporations. The second is the conviction that international economic relations and policies are predicated on political factors, such as the comparative power of states and the influence of domestic interest groups. The third is the special emphasis that is placed on the persistent and widening differences in per capita incomes between the world rich and poor nations; and the role of nation size and power in explaining the division of gains to trade and investment. Lastly, they tend to agree on the necessity for understanding trade policy outcomes as the results of the conflict between classes and interest groups" (Adams \& O’Hara, 1999, pp. 570-571). Assim, é razoável afirmar que os trabalhos de Tavares, a partir do artigo de 1985, inaugurador de novo objeto de pesquisa, são consistentes com os temas da EPI. Nesta mesma linha, ver ainda Tavares (1992), Tavares \& Melin (1997) e Tavares \& Belluzzo (2004).
} 
tardio, sem que a hierarquia geopolítica se sobreponha necessariamente à da geoeconomia (Tavares, 2000, pp. 131-132). ${ }^{3}$

As contribuições de Tavares possuem como referência as obras de vários pensadores da tradição da Economia Política, tais como Marx, Keynes, Schumpeter, Kalecki e Steindl, no âmbito da teoria econômica mais geral, bem como dos autores que se debruçaram sobre a questão do subdesenvolvimento periférico (com base na análise estruturalista), como Raul Prebisch, Aníbal Pinto e Celso Furtado, entre outros.

O objetivo deste artigo é identificar os aspectos metodológicos e as principais referências teóricas no pensamento econômico de Maria da Conceição Tavares. Apresentaremos, em linhas gerais, o diálogo crítico da autora com as vertentes da Economia Política fundadoras de sua obra. Embora Tavares dialogue com vários economistas, como Joan Robinson, Steindl, Schumpeter, entre outros, este artigo concentrar-se-á na interação intelectual com Marx, Keynes e Kalecki.

\section{CONSIDERAÇÕES PRELIMINARES: A QUESTÃO DO MÉTODO}

No que se segue, procuraremos identificar os principais aspectos metodológicos que norteiam os trabalhos de Tavares.

\section{A “visão” de Tavares}

Uma peculiaridade metodológica do pensamento econômico de Tavares reside no amálgama entre a construção teórico-analítica em simultâneo à interpretação histórica. Foi a partir disto que propôs uma interpretação inédita da dinâmica da industrialização brasileira, a partir de uma perspectiva heterodoxa que combinou teoria econômica e história, frontalmente distinta das análises econômicas convencionais.

A utilização do conceito de "visão" (vision) de Joseph Schumpeter (1954) ajuda-nos a esclarecer como a trajetória intelectual de Tavares esteve condicionada por uma certa visão acerca do funcionamento das economias capitalistas. Para Schumpeter (1954, pp. 41-42) a "visão" (que também chama de "concepção") de um determinado economista consiste em um "ato cognitivo pré-analítico" que direciona sua "análise econômica". Esta última é entendida como um conjunto de "técnicas", as quais podem ser classificadas em quatro campos: história econômica, estatística, teoria econômica e sociologia econômica (Schumpeter, 1954, p. 12). O esforço de análise propriamente dito tem lugar, necessariamente, depois deste ato cognitivo pré-analítico, o qual fornece a matéria-prima para a empreitada analítica. Há uma precedência temporal inescapável da visão em relação ao aparato analítico. Além do

\footnotetext{
${ }^{3}$ Para uma interpretação do lugar que ocupa as contribuições de Tavares na "economia política radical latino-americana”, ver Vernengo (2006).
} 
mais, a visão é "ideological almost by definiton" (Schumpeter, 1954, p. 42). ${ }^{4} \mathrm{Na}$ verdade, poderíamos acrescentar, esta ideia de visão procura, no fundo, expressar aquela necessidade vital do pensador/observador de extrair significado do mundo que o circunda, isto é, desvendar, através do entendimento consciente, o funcionamento de estruturas, relações e mecanismos subjacentes às "camadas" de realidade.

A obra de Tavares é exemplar neste aspecto de que, em princípio, a "visão das coisas" precede o trabalho analítico, o qual acaba tornando-se uma forma de implementar uma determinada visão, para posteriormente caminharem juntas, passo a passo, visão e análise, uma se alimentando da outra, em uma relação dinâmica de troca constante. Em sua obra encontra-se arraigada sua visão do funcionamento das economias capitalistas contemporâneas, em particular das economias capitalistas periféricas latino-americanas (com o Brasil como um caso ao mesmo tempo emblemático e específico). Estas últimas, em virtude de sua inserção na divisão internacional do trabalho, historicamente determinada, possuem como característica definidora o fato de serem desiguais, subordinadas e heterogêneas.

A partir da interpretação das contribuições dos economistas que elegeu como referência para suas reflexões críticas, Tavares assinala aquilo que é da essência do funcionamento do sistema econômico. Em seus próprios termos, um traço constitutivo do sistema capitalista é a "impossibilidade" de autorregulação pela concorrência de capitais, já que o sistema se afasta de sua "origem" e se torna cada vez mais "arbitrário", menos autorregulável pela força destruidora de sua expansão. Sua regulação se torna, pois, cada vez mais política. Isto é, o capitalismo é cada vez mais "regulável" pelas relações de "poder" - que é exatamente o que lhe confere tanto uma dimensão de incerteza e instabilidade, quanto de regenerescência (ainda que traumática) (Tavares, 1978, pp. 69-70).

A economia política foi um dia uma "ciência moderna" por excelência; na realidade, disputou com a física o privilégio de inaugurar a época moderna. Depois se distanciou da política e optou pela racionalidade do cálculo econômico, se converteu em uma "pobre ciência" da autorregulação dos mercados (Tavares, 1991, p. 66).

Há, portanto, um leitmotiv importante que dá consistência à sua "visão": a impossibilidade de autorregulação dos mercados em uma economia capitalista. Assim, modelos de equilíbrio geral, ou qualquer teoria que tenha como crença uma suposta autorregulação dos mercados, uma propriedade dinâmica do sistema (da economia como um todo) produzida pela ação racional (leia-se otimizadora) de indivíduos autointeressados, são instrumentos analíticos inadequados para examinar a realidade capitalista. Tavares rejeita qualquer análise que tenha como referência a ideia de equilíbrio. O capitalismo é inerentemente instável e possui trajetória incerta. Ademais, não pode ser analisado a partir de formulações gerais aplicadas de forma mecânica para todos os países, independentemente de sua especificidade histórica.

\footnotetext{
${ }^{4}$ Como afirma Dow, "How the world is understood will govern the particular choice of methodology, and in turn the range of methods to be used" (Dow, 2003, p. 14).
} 
A visão subjacente não é a de um "indivíduo" que, ao tomar decisões "ótimas", faz atuar, no agregado, uma mão invisível que engendra, inevitavelmente, o bem-estar dos povos. Ao contrário, o personagem fundamental desta trama é o "capitalista", o agente-chave de um processo que fixa a identidade do capitalismo enquanto episodio único na história da humanidade. Este processo decorre do esforço contínuo em acumular e valorizar capital (riqueza em sua forma mais líquida) através da extração de trabalho não pago. Desta visão erige-se uma análise das crises sistêmicas a que a economia se vê periodicamente sujeita.

Neste contexto, se o sistema não se autocorrige (nem no curto nem no longo prazo), se a instabilidade é imanente, o Estado como agente regulador e estabilizador adquire, desde cedo, importância crucial em seu pensamento (e, diga-se de passagem, também as relações de poder intra e inter-Estados): "o caráter contraditório do processo de expansão capitalista não pode ser apreendido em suas dimensões mais relevantes sem passar pelo esclarecimento do papel do Estado como mediador dessas contradições” (Tavares, 1972, p. 22). Assim, o Estado, através de políticas ativas de intervenção na esfera econômica (e social), torna-se a instituição central capaz de transformar um sistema intrinsecamente instável, produtor inevitável de desigualdades e assimetrias, em "capitalismo organizado".

\section{Um modo de pensamento babilônico}

Um aspecto interessante que nos parece digno de ser abordado diz respeito ao "modo de pensamento" da autora. Utilizaremos, para isso, a proposta de delimitação de Sheila Dow $(1996,2003)$, que visa esclarecer a abordagem metodológica presente (implícita ou explicitamente) na análise econômica dos diversos autores.

$\mathrm{O}$ termo modo de pensamento (mode of thought) pode ser entendido da seguinte forma:

the way in which arguments (or theories) are constructed and presented, how we attempt to convince others of the validity or truth of our arguments. It is concerned as much with the rhetoric used as means of communication as with the logical structure of the argument. It [...] influences our judgement as to what constitutes an acceptable methodological position (Dow, 1996, p. 10).

Segundo Dow, há dois modos de pensamento: o "Babilônico" e o "Euclidiano-Cartesiano". O pensamento babilônico não está organizado a partir de um conjunto de axiomas, mas está orientado pelas especificidades de cada problema a ser tratado. Ao invés de construir um único sistema lógico (formal e generalizável), o pensamento babilônico faz recortes da realidade, com o propósito de formular análises parciais da mesma. Essas análises podem ser estatísticas ou mesmo baseadas numa abordagem meramente histórica, dependendo de sua conveniência para o estudo do objeto. Assim, o estilo babilônico de pensar está condicionado pelo problema que se pretende investigar, emprega um conjunto mais amplo de 
métodos adequado ao problema e estes métodos não podem ser combinados e reduzidos a um argumento dedutivo formal sem alterar drasticamente sua natureza (cf. Dow, 1996, p. 13).

O modo de pensar babilônico é visto como um "sistema de pensamento aberto" (open system of thought), em contraposição ao modo de pensamento cartesiano-euclidiano, que consiste num "sistema de pensamento fechado" (closed system of thought), baseado em um conjunto de axiomas formulados através de um único método, o matemático. Como consequência, a análise baseada no método cartesiano-euclidiano tende a abstrair importantes "problemas práticos" de forma a gerar soluções universais dentro do domínio da abstração. Em outras palavras, são as "regras internas”, e não o recurso à realidade (que exprimiria uma orientação filosófico-metodológica realista), que condicionam o sistema lógico (Dow, 2003, p. 12). Já um sistema de pensamento aberto abre espaço para inúmeras linhas de argumentação e métodos.

Assim, é possível afirmar que o "modo de pensamento" de Tavares é, evidentemente, o babilônico. A partir de uma perspectiva "histórico-estrutural" (na tradição cepalina), Tavares reconhece a importância das especificidades históricas (e das relações de poder intra e inter-nações) para tratar das questões pertinentes ao seu principal objeto de estudo, as economias periféricas latino-americanas. Isto é, a análise econômica de Tavares não se baseia em um "sistema fechado", axiomático, através da construção de modelos matemáticos, que, em tese, permitiria "descobrir" (e aplicar) leis gerais de validade universal; ao contrário, tem como base as condições estruturais e históricas das economias latino-americanas.

O mundo real das economias capitalistas sobre o qual se debruça não é governado por leis universais. Assim como a economia evolui, nosso conhecimento em relação a ela também sofre mudanças importantes. A partir desta orientação metodológica, a autora desenvolveu um instrumental analítico "aberto" como forma de entender a dinâmica das economias periféricas. ${ }^{5}$

\section{O método histórico-estrutural}

Um aspecto central das ideias cepalinas que influenciaram a trajetória intelectual de Tavares é o chamado "método histórico-estrutural”, que advém "de un

\footnotetext{
5 “A ideia de separar, como economista, teoria, instituições e Economia aplicada não me passava pela cabeça! O sujeito que não é capaz de, primeiro, separar os níveis, mas ao mesmo tempo juntá-los, não é economista!" (Tavares, 1996, p. 132). Este tipo de preocupação remonta aos primórdios de sua obra. Para Tavares, é necessário adotar as seguintes "perspectivas": "soltar as amarras das 'inibições metodológicas' e deixar livre a imaginação e o espírito criador, num esforço de interpretação, embora parcial e provisório, da nossa complexa realidade social. Não temer a disciplina do recorte analítico específico e, ao mesmo tempo, ousar enfrentar os problemas em sua dimensão global, sem se deixar levar por 'totalizações' fáceis e vazias. Não 'neutralizar' as Ciências Sociais, limpando-as de qualquer 'desvio' ideológico e tornando-as ciências 'positivas'; usar o impulso ideológico no sentido do desmascaramento da própria ideologia contida naquela posição" (Tavares, 1972, p. 25). Podemos interpretar esta passagem como um verdadeiro manifesto metodológico para as análises teórico-empíricas que, a partir daí, a autora empreenderia.
} 
fértil cruce entre un método esencialmente histórico e inductivo, por un lado, y una referencia abstracto-teórica propia - la teoría estructuralista del subdesarrollo periférico latinoamericano - por el otro" (Bielschowsky, 1998, p. 21). Em várias ocasiões, Tavares reconheceu a importância desta abordagem em seu pensamento. ${ }^{6}$

A abordagem histórica dos problemas da periferia latino-americana foi utilizada pela teoria do subdesenvolvimento de Prebisch, que tinha como propósito examinar o modo peculiar de como se dava o ajuste interno da estrutura produtiva dos países latino-americanos em resposta aos choques externos. Essa peculiaridade residia no fato de que esse ajuste estava condicionado por uma estrutura econômica e institucional subdesenvolvida, herdada do período exportador (Bielschowsky, 1998, p. 22). Na visão cepalina, as estruturas periféricas latino-americanas condicionam a trajetória futura (desconhecida ex ante) da economia. O enfoque histórico-estruturalista implica um método de geração do conhecimento voltado ao comportamento de agentes sociais e instituições, mais próximo a um procedimento indutivo do que aos métodos abstrato-dedutivos convencionais (Bielschowsky, 1998, p. 24).

Segundo Nora Lustig (1988, pp. 36-37), a "paternidade teórica" do estruturalismo é múltipla. O pensamento estruturalista é fruto de algumas tradições da economia política, tanto em sua forma mais "radical" (tradição marxista), quanto à sua vertente "reformista" (enfoques keynesianos, kaleckianos e institucionalistas). ${ }^{7}$

Tavares também chama a atenção para este aspecto da pluralidade teórica subjacente ao método cepalino: "Quem é do método histórico-estrutural pode usar elementos teóricos de várias escolas e tentar integrá-las. [...] O método 'histórico-estrutural' no pensamento econômico latino-americano deve-se a [Prebisch] e a Furtado. E nós todos, seus discípulos, somos histórico-estruturais, todos!” (Tavares, 1996, pp. 133-134). Assim, embora ao longo de sua trajetória intelectual Tavares tenha feito revisões críticas de seus próprios trabalhos, a abordagem histórico-estrutural esteve presente de forma recorrente e consistente.

$\mathrm{Na}$ sequência, abordaremos o diálogo de Tavares com aqueles autores que foram referência decisiva para sua obra.

\footnotetext{
6 “A CEPAL serviu para me dar uma preocupação nova sobre o que é a formação histórica, a evolução histórica, o papel dos agentes econômicos em uma sociedade, como é que se desenvolve, portanto, dentro de uma perspectiva estrutural histórica. Isso eu não tinha, devo a CEPAL" (Tavares, 1996, p. 132).

7 "Las raíces clásicas del pensamiento estructuralista se pueden encontrar en la tradición marxista/ schumpeteriana en el sentido de que para el estructuralismo el sistema capitalista de libre empresa no es sistema armónico sino inherentemente conflictivo, y su desarrollo no ocurre de manera suave sino que se da en forma de saltos, generándose innumerables desequilibrios en el proceso mismo" (Lustig, 1988, pp. 36-37). Sobre a influência das ideias keynesianas e institucionalistas sobre a teoria estruturalista, ver também Saad-Filho (2005, p. 132).
} 


\section{MARX E O MOVIMENTO DO "SOL"}

Embora em grande parte da obra de Tavares seja possível constatar a influência das ideias de Karl Marx, é em "Um Contraponto à Visão da Autorregulação da Produção Capitalista" (Tavares, 1978, cap. 2; Tavares, 1983a) que faz uma releitura da teoria marxista do valor, entendida como uma "teoria da valorização do capital".

Para Tavares, o modo de produção capitalista possui um caráter contraditório:

O capital é [...] "uma contradição em processo", que tende "lógica" e historicamente para o seu "conceito", para sua "forma mais geral e aparente" que se afasta cada vez mais de sua "origem", o valor-trabalho (Tavares, 1978, p. 58).

O desenvolvimento das forças produtivas capitalistas, ao reduzir o número de horas de trabalho necessárias à produção de qualquer mercadoria, tende a diminuir a necessidade de trabalho assalariado "vivo", que constitui a fonte do valor, ao mesmo tempo em que tende a diminuir o valor do trabalho "morto", os meios de produção produzidos (Tavares, 1978, p. 59). Entretanto, se, por um lado, o capital se contrapõe de modo antagônico ao trabalhador, tendendo a negar o trabalho, por outro, o "movimento real do capital" se afasta cada vez mais de sua determinação conceitual, o valor-trabalho. Isso não significa, entretanto, o abandono da lei do valor, mas sim a sua própria realização enquanto "lei de valorização".

$\mathrm{O}$ entendimento desse caráter contraditório do capital permite, segundo Tavares, esclarecer o conceito de lucro. Este, segundo a autora, é inerente ao processo de produção capitalista na sua forma completa ("reprodução ampliada do capital”) e, por isso, "não pode ser 'deduzido' da 'mais-valia' ou do 'excedente', nem contabilizado pelo número de horas do 'sobretrabalho"” (Tavares, 1978, p. 55). O lucro requer a valorização, em termos monetários, daqueles componentes do capital que foram previamente utilizados (força de trabalho e meios de produção). Portanto, por ser uma categoria que exprime a valorização do capital, o lucro capitalista é uma "totalidade problemática", que implica a existência de "três movimentos lógicos do processo de valorização". Em primeiro lugar, a apropriação do trabalho abstrato pelo capital (determinação da taxa de mais-valia); em segundo lugar, sua "transformação" em preços de produção (determinação da taxa média de lucro); por fim, a transfiguração do capital em uma mercadoria singular, o dinheiro, onde se dá a determinação da taxa efetiva de lucro (cf. Tavares, 1978, pp. 57-58).

A tendência do capital à sua "forma mais geral e aparente", o que significa que "no seu movimento de autoexpansão e valorização permanente (o capital) termina por encontrar-se prisioneiro de si mesmo", isto é, "o dinheiro tentando valorizar o dinheiro" (Tavares, 1978, p. 68), é a ideia-chave para a compreensão de um aspecto central, desenvolvido de forma sistemática ao longo de sua obra, e 
que aparece já em Tavares (1972): a lógica financeira do processo de valorização do capital sobrepondo-se à sua dimensão produtiva.

O desenvolvimento das instituições financeiras e, por sua vez, a criação de novos instrumentos de dívida (títulos financeiros privados e públicos), torna possível a valorização contábil "fictícia" do capital. Neste processo, a valorização na esfera financeira tende a superar a valorização na esfera da produção:

O desenvolvimento das relações de crédito e a invenção periódica de novas "instituições" financeiras, que permitem a "capitalização", isto é, a valorização contábil do dinheiro pelo dinheiro, só encontra paralelo com o próprio desenvolvimento inexorável da técnica na direção de tornar "inútil" o trabalho produtivo. A parte "ativa" do dinheiro, que entra na circulação de mercadorias requeridas pelo processo produtivo, vai diminuindo, e o capital financeiro fictício se torna, cada vez mais “ativamente", passivo (Tavares, 1978, p. 66). ${ }^{8}$

Os "limites" à acumulação decorrem do próprio processo de valorização do capital. São, portanto, elementos endógenos - e não exógenos, como o esgotamento dos recursos naturais e da força de trabalho - do sistema capitalista que engendram sua própria crise:

A acumulação de capital pára por si mesma. ... Para pela força ou fraqueza da concorrência entre os vários capitais; pela acumulação de capacidade ociosa, que se produz no descompasso entre o investimento que atrai investimento em cadeia e o escoamento da produção corrente; pela anarquia da produção capitalista, que move as expectativas de rentabilidade para cima, quando tudo vai bem, e as reverte bruscamente, quando o endividamento é excessivo e o risco se torna inaceitável. [...] A acumulação não esbarra nos salários ou na falta de mão de obra, esbarra em si mesma. O capital é o limite de si mesmo, advertia Marx (Tavares, 1978, pp. 30-31).

Nesse mesmo ensaio, Tavares, ao criticar, com base na lei do valor, a ideia de autorregulação da economia capitalista utiliza uma metáfora inusitada para explicar o movimento do capital:

a lei do valor não é apenas a lei que permite determinar a "taxa média de lucro" que manteria a produção técnica e social girando em torno do Sol - O Capital - como num Sistema Copernicano aproximando-se e afastando-se dele, no seu movimento autorregulado. É uma lei mais profunda e dialética, como as "leis modernas" da física e da energia, da

\footnotetext{
${ }^{8}$ Vale lembrar que ideia semelhante também está presente no Tratado sobre a Moeda de Keynes (1930), onde este distingue duas esferas de circulação de moeda: a industrial e a financeira.
} 
expansão do universo, que transformam o próprio "Sol" por dentro, que fazem explodir os sóis, que fazem do "universo" um sistema em expansão cheio de "buracos" (Tavares, 1978, p. 68).

Em suma, em sua reinterpretação de Marx Tavares enfatiza: o caráter contraditório do movimento do capital; a tendência do capital a sua "forma mais geral"; a preponderância do capital financeiro sobre o capital produtivo; os obstáculos endógenos à acumulação capitalista. Esses aspectos corroboram sua interpretação acerca da impossibilidade de autorregulação, fornecendo consistência analítica à sua "visão". Destarte, ao privilegiar, nos termos apontados, o "movimento do capital", é razoável inferir que na economia política de Tavares, o sujeito da História, se houver algum, é o capital, e não o trabalho.

\section{AINDA NA TRADIÇÃO DE MARX: O CAPITAL FINANCEIRO}

Em Tavares \& Belluzzo (1980), a autora procura esclarecer o conceito de capital financeiro e discutir a dimensão por este assumida no capitalismo contemporâneo. Para tanto, as referências utilizadas são, além de Marx, Rudolf Hilferding e John Hobson.

Para Tavares, a elaboração do conceito de capital financeiro pode ser encontrada na seção V do terceiro volume de $\mathrm{O}$ Capital, onde é tratado "o problema da autonomização do capital-dinheiro, sob a forma de capital a juros" (Tavares \& Belluzzo, 1980, p. 113).

Marx, além de decompor os elementos que constituem o modo de produção capitalista, ressaltando as três formas em que se apresenta o capital (capital-dinheiro, capital-mercadoria e capital-produtivo), analisa as possibilidades de o sistema capitalista assumir uma trajetória temporal em uma "direção determinada". De acordo com a ideia de uma "lei geral da acumulação capitalista", o capital necessita de expansão e valorização contínuas, o que extrapola o processo elementar de circulação e reprodução. Essa necessidade condiciona o surgimento do capital a juros.

A concentração e centralização dos capitais, consequência natural desta lei geral da acumulação capitalista, materializam-se através da "ampliação e externalização crescentes do capital a juros”, em que há ascendência crescente do sistema de crédito sobre as esferas mercantil e produtiva (Tavares \& Belluzzo, 1980, p. 114). Para se expandir e fortalecer, o sistema capitalista necessita cada vez mais de um capital na sua forma "livre", líquida e centralizada, que lhe permita buscar, sem obstáculos, as novas oportunidades de lucro.

Com base nesta análise de Marx, Hilferding também elabora um conceito de capital financeiro, a partir de um duplo movimento analítico. Em primeiro lugar, propõe uma formulação mais geral com o objetivo de caracterizar uma etapa mais avançada da concentração de capitais. Em seguida, sugere uma descrição morfológica do capitalismo monopolista alemão, caracterizado por uma forma específica de interação entre os bancos e as grandes empresas, origem dos grandes cartéis alemães. 
Por sua vez, Hobson debruça-se sobre a economia americana, que seria o paradigma do "capitalismo moderno", e que assume a forma de um "capitalismo trustificado", a partir das transformações ocorridas nesta economia na virada do século XIX para o XX, com o capital financeiro tendo papel decisivo nesse processo. A gênese e desenvolvimento da corporação americana são o embrião nacional do subsequente desdobramento transfronteiras do grande capital (Tavares \& Belluzzo, 1980, p. 116).

Hobson, assim como Hilferding, enfatiza o papel crucial do capital financeiro no entendimento de como emerge a grande empresa americana, bem como a natureza de sua futura posição hegemônica. Além das mudanças na organização das empresas, surge também uma "classe financeira", que tende a concentrar nas mãos dos grandes bancos um poder cada vez mais amplo na gestão estratégica das "relações 'intersticiais' (intersetoriais e internacionais) do sistema" (Tavares \& Belluzzo, 1980, p. 116). Essa classe financeira representa a associação estratégica entre bancos e empresas para formar a grande corporação americana que detém sob seu controle as atividades estratégicas (de então): minas, transporte, banco e manufaturas.

Assim, a ampliação e consolidação de práticas especulativas só se tornam possíveis com o aumento em grande escala do crédito, o que confere amplo poder à classe que o controla (os bancos). O tamanho e a capacidade de crescimento das grandes corporações "trustificadas" decorreriam da dimensão financeira na organização do capitalismo monopolista, muito mais do que da base técnica.

Ademais, o esgotamento das possibilidades de lucro dentro da própria indústria impele os capitais para fora, levando a um processo de internacionalização do capital. Mesmo com um amplo "espaço nacional monopolizado", defendidos pelos Estados nacionais, o incremento dinâmico dos lucros excedentes requer a procura de espaços adicionais de valorização ("mercados externos"), tanto para mercadorias quanto para investimentos diretos e finanças (Tavares \& Belluzzo, 1980, p. 120).

A internacionalização do capital confere um papel especial ao Estado Nacional enquanto agente articulador dos capitais locais e da empresa multinacional, buscando defender os primeiros e garantir a reprodução ampliada do capital internacional. Para isso, é importante a atuação do Estado no controle do padrão monetário nacional, "o único padrão de referência contábil e de liquidação interna de débitos”, tornando-se, portanto, o meio por excelência de circulação do capital e, consequentemente, o único veículo adequado à "reprodução ampliada" (Tavares \& Belluzzo, 1980, p. 121). ${ }^{9}$

\section{KALECKI E A DINÂMICA DO CAPITALISMO (BRASILEIRO)}

A visão de Michal Kalecki sobre a dinâmica econômica capitalista está articulada em Tavares $(1974 ; 1978)$. Dois aspectos do pensamento de Kalecki são resga-

\footnotetext{
${ }^{9}$ Tavares voltaria a se debruçar sobre as contribuições de Hobson em Tavares (1983b).
} 
tados para compor uma estrutura analítica com o objetivo de reinterpretar o processo de industrialização no Brasil: o princípio da demanda efetiva e os esquemas trissetoriais da dinâmica interindustrial.

Para compreender a industrialização no Brasil, privilegiando os aspectos endógenos da acumulação de capital, Tavares vale-se do princípio da demanda efetiva, ${ }^{10}$ segundo o qual as economias não enfrentam problemas do lado da oferta, e sim pelo lado da demanda, o que pode caracterizar uma situação de "insuficiência da demanda efetiva" (Tavares, 1974, p. 49).

Tavares destaca que o aspecto crucial da demanda efetiva é o investimento enquanto instrumento de expansão da capacidade produtiva e da acumulação de capital. Das variáveis de gasto, é importante também o consumo capitalista, como enfatizado por Kalecki, pois o mesmo é um "elemento dinâmico fundamental para determinar e manter uma taxa histórica de lucro e de acumulação a longo prazo" (Tavares, 1974, p. 33). Portanto, tem um papel a desempenhar na realização dos lucros no processo de acumulação.

Para Tavares, o processo de oligopolização da estrutura industrial expressa uma tendência de longo prazo, podendo assumir formas distintas. Podem se configurar aí o oligopólio puro ou concentrado (à la Steindl e Bain), a competição com base em inovações tecnológicas (à la Schumpeter), o oligopólio diferenciado (à la Sylos-Labini), e a articulação oligopólica com hegemonia do capital financeiro (à la Hilferding).

A utilização dos esquemas de três setores de Kalecki é funcional para explicar a interpretação de Tavares do "crescimento desequilibrado" (Tavares, 1978, p. 25). Essa ideia tornou-se a base da nova visão da autora sobre a dinâmica cíclica da industrialização brasileira, presente em Tavares (1974; 1978).

Se o crescimento do DI e do DII superar o crescimento do DIII, os lucros crescerão relativamente mais que os salários, o que se traduz em uma expansão da capacidade produtiva em ritmo maior que o crescimento da produção e da renda corrente. Isto gera uma queda no grau de utilização da capacidade produtiva que pode induzir a uma queda na taxa de investimento, implicando em aumento de capacidade ociosa por toda a economia e, por consequência, queda dos lucros (Tavares, 1978, pp. 25-26).

Portanto, é a queda no ritmo de expansão do capital (investimento) que desencadeia a "superacumulação de capital":

A ampliação do DI tende a parar, ao produzir-se um aumento da sua capacidade ociosa, a qual freia os novos projetos de investimento por reduzir a taxa de rentabilidade esperada. É a queda no nível de investimento que determina a queda na taxa de lucro efetiva e não o contrário.

\footnotetext{
${ }^{10}$ Embora uma versão do princípio da demanda efetiva esteja presente em Keynes, em Acumulação de Capital e Industrialização no Brasil a autora baseia-se em Kalecki: "Nossa visão macroeconômica central deriva-se, no entanto, de Kalecki, que é um contemporâneo de Keynes, mas tem sobre ele a vantagem de uma simplicidade analítica maior e de uma formulação rigorosa da Dinâmica Econômica” (Tavares, 1974, p. 16).
} 
O consumo dos capitalistas, que vai crescendo com os lucros, atrás do investimento, tende também a ser freado junto com ele. O nível de consumo capitalista pode sustentar-se, porém, graças às rendas capitalistas acumuladas, o que não ocorre com parte do consumo dos trabalhadores. A mão de obra empregada na construção de nova capacidade produtiva é despedida; diminui a demanda do DIII, que por sua vez também tende a despedir trabalhadores, caindo em consequência o nível geral de emprego e a massa de salários. O excesso de capacidade que se gerou com a desaceleração do investimento generaliza-se para toda economia ( $\mathrm{Ta}-$ vares, 1978, pp. 28-29).

Tavares procurou contextualizar a visão de Kalecki, adaptando-a à realidade das economias periféricas "semi-indutrializadas". A diferenciação do consumo dos capitalistas e dos trabalhadores é importante, segundo Tavares, porque ajuda a resolver problemas de reprodução do capital em certas etapas da "industrialização avançada" (Tavares, 1974, p. 34). Em economias de capitalismo desenvolvido, os bens de consumo dos trabalhadores, embora menos sofisticados, não se diferenciam, no que se refere à estrutura produtiva, dos bens de consumo capitalista. Mas, para economias subdesenvolvidas, essa diferenciação, além de não resolver as contradições inerentes à reprodução ampliada do capital, cria uma contradição adicional, específica a estas economias, entre a expansão do consumo básico dos trabalhadores e a diferenciação crescente do consumo capitalista. Essa diferenciação produtiva favorece a taxa de acumulação no curto prazo, mas não diminui, se não agrava, os desequilíbrios dinâmicos na estrutura setorial de crescimento a longo prazo.

\section{KEYNES E A INSTABILIDADE INERENTE DO CAPITALISMO}

A partir de sua interpretação da obra de John Maynard Keynes, Tavares extrai algumas das ideias mais importantes que sustentam sua convicção quanto à impossibilidade de autorregulação da economia capitalista. Deriva daí a ideia da economia capitalista (inerentemente instável) como uma "economia monetária da produção”, em que a incerteza tem um papel importante a desempenhar.

A incerteza no horizonte de cálculo capitalista implica ressaltar o papel determinante e instável do investimento na dinâmica capitalista. O caráter determinante do investimento está baseado no princípio da demanda efetiva, a ideia de que as variáveis de gasto determinam as variáveis de renda. Nesse sentido, o investimento torna-se central para a determinação do nível de renda da economia.

Se, de um lado, o investimento é a variável estratégica determinante da demanda agregada, de outro, é o principal elemento instabilizador do capitalismo. Os fatores determinantes do investimento, por serem influenciados pelas expectativas dos agentes acerca de um futuro incerto, são incapazes de garantir uma trajetória estável a essa variável. Tavares expressa da seguinte forma esse duplo caráter do investimento, estratégico e instabilizador:

O investimento não é, pois, apenas uma categoria de demanda efetiva. [...] É fundamentalmente uma categoria dinâmica, é o instrumento 
da expansão da capacidade produtiva, da acumulação de capital, é o elemento cíclico por sua própria natureza. Se crescer demais, não se pode manter, porque termina por gerar capacidade ociosa, que deprime a taxa de rentabilidade do capital, tanto a esperada como a efetiva. Se crescer de menos, tampouco pode manter-se, porque não gera renda suficiente para comprar a própria produção ampliada (Tavares, 1978, p. 31).

Com base no princípio da demanda efetiva, Tavares (1978, pp. 32 e ss.) afirma que não se sustenta a ideia de "insuficiência de poupança" para explicar as flutuações do investimento. O desenvolvimento do sistema de crédito, ao exercer papel fundamental no financiamento do investimento, faz com que a poupança, a renda não gasta, não seja determinante para a realização do investimento. Assim, em uma economia capitalista, quanto maior o gasto agregado, maior a renda gerada e, portanto, maior o montante de recursos para as operações de crédito, que, por sua vez, não estão limitadas pelo montante de poupança prévia dos agentes. A poupança, de acordo com Keynes (e Kalecki), deve ser compreendida como um resíduo da renda (é a renda não gasta, definida ex post). Nesta abordagem, a poupança jamais "determina" o investimento, mas, sim, possui uma equivalência contábil com o mesmo. Assim, a causalidade (a relação de determinação) deve ser entendida, ao contrário do que consta na análise convencional, a partir do investimento (gasto) para a poupança (renda não-gasta), e não o contrário.

Os capitalistas gastam em investimento e em consumo e esse nível de gasto determina o montante de lucros num período de produção (ex post). Os lucros não podem ser determinados previamente (ex ante). Os investimentos são feitos ou com capital próprio, decorrentes de lucros acumulados no passado ("poupança" das empresas), ou com capital de terceiros (endividamento), e são condicionados pelas expectativas dos capitalistas quanto ao lucro esperado (comparado ao risco do endividamento).

No financiamento do investimento, os capitalistas não podem contar apenas com suas "poupanças prévias" (Tavares, 1978, p. 36). Eles precisam também do sistema financeiro, que deve ser capaz de reunir e transformar as poupanças em excesso das firmas ou das famílias em ativos financeiros. Esses ativos permitem a valorização fictícia do capital, que é tanto maior quanto mais desenvolvidas forem as relações financeiras de uma dada economia.

Somente uma parcela dos ativos financeiros é, de fato, "ativa". Esta parte corresponde à "dívida primária nova", que se destina a financiar o setor produtivo da economia. A remuneração desse capital financeiro é paga com os juros que o setor financeiro apropria de parte do lucro produtivo. Mas só serão efetivamente pagos uma vez maturados os investimentos e se os lucros forem realizados. A dívida, portanto, precede o investimento (Tavares, 1978, p. 37).

Ainda com base em Keynes, Tavares trata da questão da crise de crédito. $\mathrm{O}$ grande problema do endividamento, segundo a autora, é o fato de ele preceder a geração da renda e dos lucros. A sustentação da renda e dos lucros, por sua vez, requer que os investimentos produtivos cresçam de modo a alimentar a "parte 
ativa do capital", aquela relacionada ao financiamento da produção, do investimento e do consumo. Se os investimentos declinarem e, por consequência, os lucros não se realizarem, o peso da "parte passiva do capital" se manifesta, deprimindo ainda mais o movimento real do capital produtivo (Tavares, 1978, p. 40). Nesse sentido, é a queda no nível dos investimentos que explica a reversão do ciclo.

$\mathrm{Na}$ visão de Keynes, assegura Tavares, a crise decorre não de uma elevação da taxa de juros, em virtude de um aumento da preferência pela liquidez, mas do colapso da eficiência marginal do capital. Avaliações pessimistas e a incerteza em relação ao futuro fazem com que a retomada da confiança nos negócios seja algo de difícil gestão numa economia de "capitalismo individual" (Tavares, 1978, p. 41).

Assim, enquanto as expectativas que guiam as decisões de investimento forem alvissareiras, as decisões de endividamento continuam, mesmo em caso de elevações nas taxas de juros. Se os investimentos declinarem (e com eles a renda), a carga da dívida torna-se insuportável e a crise financeira se manifesta, aumentando a preferência pela liquidez dos agentes. A crise atinge, de início, as empresas financeiramente mais frágeis e, dependendo de sua intensidade, pode, através de um efeito dominó, atingir empresas maiores e os grandes bancos financiadores destas (Tavares, 1978 , p. 42$).{ }^{11}$

\section{AINDA NA TRADIÇÃO DE KEYNES: CONTRIBUIÇÕES PÓS-KEYNESIANAS}

A interpretação de Tavares do princípio da demanda efetiva de Keynes e sua análise mais geral acerca do fenômeno inflacionário credenciam-na a figurar como uma autora que contribuiu de forma decisiva para a constituição e disseminação das ideias pós-keynesianas no Brasil. Quando for escrita a história do pensamento pós-keynesiano no Brasil, certamente Tavares ocupará um papel destacado. No que se segue, reconstituiremos suas intervenções sobre estes dois temas, ambos em coautoria com Luiz Gonzaga Belluzzo.

\section{O princípio da demanda efetiva}

Em Tavares \& Belluzzo (1981), a autora defende a tese de que o princípio da demanda efetiva "propõe uma visão estruturada e determinada da dinâmica capitalista" (Tavares \& Belluzzo, 1981, p. 112). Este conceito permite entender a influência das flutuações do investimento sobre a demanda agregada e, consequentemente, o nível de produção, renda e emprego.

Para Tavares, o princípio da demanda efetiva não depende das hipóteses de subconsumo ou de excesso de poupança. O consumo depende diretamente do montante de renda. Um declínio da renda, decorrente de um declínio do investi-

\footnotetext{
${ }^{11} \mathrm{O}$ leitor mais atento deve perceber aí um inconfundível tom minskyano, mas Minsky, embora referência importante em outros trabalhos da autora, em nenhum momento é citado em Tavares (1978).
} 
mento, reduz o nível de gastos com consumo e, consequentemente, aparenta produzir um excesso de bens de consumo. A renda, nesse sentido, depende diretamente do investimento, que é a variável central da dinâmica capitalista.

As flutuações do investimento, por ocasionarem variações no produto e na renda, são responsáveis pelo caráter intrinsecamente instável do capitalismo. Essas flutuações ocorrem porque o volume de inversões depende de expectativas sobre o futuro relacionadas à propensão a entesourar (preferência pela liquidez) e à rentabilidade esperada dos ativos de capital, nenhuma das quais se apoia num fundamento adequado ou seguro. Assim, uma perspectiva pessimista acerca dos rendimentos futuros aumenta também a propensão a entesourar dos agentes, o que leva, consequentemente, a uma queda dos investimentos e, por extensão, do nível de demanda agregada e renda:

As razões das amplas e repentinas flutuações do investimento nascem da própria natureza e objetivos da produção capitalista. O afã do ganho privado e a natureza anárquica das decisões intertemporais que caracteriza a busca deste objetivo levam a classe capitalista como um todo a avaliações problemáticas - para a estabilidade do sistema - quanto ao valor presente de seu capital e quanto à forma desejada de posse da riqueza. A relação entre a taxa de juros e o rendimento provável dos bens de capital recém-produzidos pode ser tal que indique ao conjunto da classe capitalista que, tanto a taxa máxima, remuneração do capital produtivo, quanto a forma mais segura, neste momento, de posse do capital sans phrase, sejam, na verdade, incompatíveis com o ritmo vigente do investimento e, portanto, com o nível atual da renda e do emprego (Tavares \& Belluzzo, 1981, p. 111).

Assim, através do princípio da demanda efetiva é possível formular uma "lei geral da dinâmica do sistema capitalista”, com ênfase na instabilidade inerente dos mercados.

\section{A dinâmica da inflação}

A influência da agenda keynesiana continuou presente nas reflexões posteriores da autora em sua discussão acerca dos determinantes da inflação nas economias modernas (Tavares \& Belluzo, 1984), que tem como referencial de análise o que chama de "paradigma keynesiano de determinação dos preços", baseado nos trabalhos de Paul Davidson (e seu uso das categorias mercados spot e forward) e John Hicks (e sua taxonomia preços fix e flex), autores associados à escola pós-keynesiana de pensamento econômico.

Nos anos 1970 e 1980 a aceleração inflacionária tornou-se uma preocupação tanto nas economias centrais, quanto nas periféricas - nessas, ainda de forma mais aguda. Os dois choques do petróleo, a ruptura das regras que constituíam a institucionalidade do sistema de Bretton Woods, e o choque dos juros agravaram a incerteza que cerca o cálculo prospectivo capitalista e a instabilidade do sistema de preços mundial.

Para Tavares, as premissas do modelo de Hicks e Davidson residiam basicamente em uma hipótese de estabilidade das variáveis-chave ao cálculo capitalista, 
garantida pela vigência de um padrão monetário internacional estável, o qual era capaz de gerar taxas "de equilíbrio" ou "normais", relativamente previsíveis, para juros e câmbio, permitindo o funcionamento do sistema de preços em qualquer economia nacional. Assim, em decorrência da sucessão de choques sobre a economia nos anos 1970, as convenções vigentes à época foram, se não destruídas, pelos menos fortemente abaladas, e, com isto, "a hipótese da estabilidade dos contratos de oferta e dos contratos de dívida, no período de produção, não se sustenta" (Tavares \& Belluzzo, 1984, p. 52).

A ruptura do padrão internacional na década de 1970 teve efeitos instabilizadores sobre as taxas de câmbio e de juros. Isto tornou limitado o modelo de fix-prices de Hicks para explicar o comportamento dos preços industriais. Com as flutuações mais exacerbadas das taxas de câmbio e de juros, a estabilidade tanto dos preços embutidos nos contratos de oferta para o suprimento de matérias-primas estratégicas (importadas e exportadas), como dos contratos de dívida, ficou comprometida. Esses contratos passaram a ser reajustados em períodos de tempo mais curtos. O horizonte temporal para o cálculo prospectivo capitalista tornou-se, portanto, mais incerto e os preços de produção, antes de natureza fix-prices, passaram a ser mais flexíveis (para cima), como forma de antecipar uma possível queda na rentabilidade do capital. Como consequência, as margens desejadas de lucro já não mais representavam um mark-up estável sobre os custos primários, tornando-se uma "margem incerta de cálculo". Com as frequentes desvalorizações cambiais e variabilidade das taxas de juros, estas margens apresentam tendência ascendente (Tavares \& Belluzzo, 1984, p. 53).

Este aumento da incerteza tornou mais problemática a estimativa do preço de oferta dos novos bens de capital, isto é, afetou de forma adversa o cálculo da eficiência marginal do capital. Os mesmos fatores que desestimulam as decisões de investimento aumentam a preferência pela liquidez. Com isto, "não se dá lugar à criação de riqueza futura (novo investimento), aprisionando montantes crescentes de liquidez à circulação financeira e restringindo a liquidez necessária à circulação industrial. Esta restrição de liquidez mais a instabilidade das taxas de juros é que inviabilizam o investimento produtivo e não os níveis absolutos das taxas" (Tavares \& Belluzzo, 1984, p. 57).

Assim, ao mostrar as limitações do modelo keynesiano de determinação de preços na nova conjuntura econômica mundial dos anos 1970-1980, Tavares não rompeu com as ideias da tradição keynesiana (não "bastarda"). Ao contrário, utilizou-as não para descartá-las, mas para fornecer uma interpretação mais geral da dinâmica da inflação, válida também para os contextos de maior instabilidade e incerteza. Constituiu-se, portanto, em um aporte analítico, atualizado e inovador, com base em hipóteses e conceitos que animam a perspectiva pós-keynesiana.

\section{CONSIDERAÇÕES FINAIS}

Embora o objetivo central deste artigo tenha sido o de resgatar as principais referências teóricas no pensamento econômico de Tavares, é oportuno ressaltar a 
importância de seus trabalhos sobre economia brasileira. A releitura dos "grandes mestres" possibilitou uma interpretação crítica da dinâmica capitalista e, a partir disso, das especificidades do capitalismo brasileiro. A reflexão teórica esteve a serviço da investigação de fenômenos concretos, no caso, a economia brasileira.

Em seu primeiro trabalho relevante (Tavares, 1963), a autora compartilha com a Cepal a visão sobre o capitalismo periférico, através da ideia de industrialização por substituição de importações. Nessa visão, o desenvolvimento econômico dos países não ocorria necessariamente em todos os lugares, seguindo as mesmas etapas. Uma vez que um grupo de países se industrializava primeiro, a assimetria das relações de poder na economia mundial relegava outros países a um papel subordinado e periférico, como os países latino-americanos. Nota-se, desde então, uma preocupação em entender as especificidades do desenvolvimento periférico, rejeitando a ideia convencional do subdesenvolvimento como etapa transitória do desenvolvimento e compartilhando a visão cepalina de subdesenvolvimento como uma configuração estrutural das economias periféricas. De economias primário-exportadoras, essas economias teriam sido estimuladas a se industrializar devido a sucessivos choques externos (Primeira Grande Guerra, Crise de 1929 etc.). Isto, além de ter reduzido drasticamente a principal fonte de rentabilidade dessas economias, gerava uma demanda por importações insatisfeita.

A solução consistiu em produzir internamente o que antes se importava, ou seja, industrializar-se por substituição de importações. Esse novo modelo era totalmente distinto do modelo primário-exportador. Em primeiro lugar, porque houve uma mudança nos componentes dinâmicos da economia. O setor externo perdeu importância relativa no processo de formação da renda nacional, enquanto aumentou a participação e o dinamismo da atividade interna. Em segundo lugar, porque enquanto as exportações eram a principal determinante exógena do crescimento no modelo anterior, o investimento passou a ser a variável endógena principal. Houve também uma mudança no papel do setor externo, que passou a contribuir para a diversificação da estrutura produtiva (importação de equipamentos e bens intermediários).

À medida que a estrutura produtiva modificava-se e a industrialização avançava, a pauta de importações tornava-se cada vez mais rígida, dada a necessidade de bens intermediários e de capital mais onerosos que os bens de consumo que antes dominavam a pauta de importações. A restrição externa, a dimensão limitada do mercado interno (que não podia comportar grandes escalas) e a inadequação da tecnologia adotada (baseada numa relação capital-trabalho elevada numa economia com abundância de mão de obra não qualificada) levaram ao esgotamento do processo de substituição de importações.

No decorrer de seu percurso intelectual Tavares reavaliou sua própria matriz teórica cepalina e incorporou novos conceitos, o que acabou por conformar uma interpretação própria e original da dinâmica capitalista brasileira.

A necessidade de se elaborar um corpo teórico alternativo surgiu, inicialmente, da crítica à tese estagnacionista de Celso Furtado, segundo a qual o dinamismo do processo de substituição de importações teria chegado ao fim, devido à incom- 
patibilidade entre o padrão concentrado de distribuição de renda e o tipo de tecnologia utilizado. Enquanto o primeiro tornava o tamanho do mercado limitado, o segundo, por estar associado a uma relação capital-trabalho elevada, exigia pouca mão de obra não qualificada e grande aporte de capital, acentuando a concentração de renda. Esses fatores levariam a economia brasileira a uma encruzilhada: ou a estagnação econômica ou a adoção de reformas socio econômicas profundas, que permitiriam o desenvolvimento em novas bases.

A crítica da autora a esta visão do capitalismo brasileiro surge em Tavares \& Serra (1971). Para os autores, a desaceleração das taxas de crescimento da economia brasileira na década de 1960 não representava uma tendência persistente à estagnação, mas, sim, consistia apenas em uma baixa cíclica que poderia ser superada. O elemento decisivo para a crise decorria da redução na taxa de investimentos, após o amadurecimento do pacote de investimentos complementares implementados no Plano de Metas (1955-1960), à semelhança de uma onda de inovações schumpeteriana que encontrara seu limite. Isso, somado à redução do nível de atividade no período 1960-63, generalizou capacidade ociosa, fazendo cair a relação produto-capital. Assim, ao final do processo de substituição de importações e, ao contrário do que defendia a tese estagnacionista, " $\mathrm{O}$ capitalismo brasileiro tinha condições para passar a um esquema de expansão cujos estímulos emanavam do próprio sistema (sem que isto significasse o enfraquecimento dos laços de dependência externa, tornando-os, pelo contrário, mais estreitos)" (Tavares e Serra, 1971, p. 172).

Embora seja possível identificar em Tavares \& Serra (1971) uma ruptura com a visão cepalina, mudanças teóricas mais substantivas surgem nas obras seguintes da autora. É somente em Tavares (1974) que elabora um corpo teórico alternativo para compreender a industrialização brasileira a partir de uma análise da dinâmica endógena da acumulação capitalista periférica.

Tavares identifica distintos "padrões de acumulação" para economias industrializadas e semi-industrializadas, que apresentariam certas particularidades na distribuição de renda. Para tanto, Tavares procurou realçar "os aspectos internos do movimento de acumulação de capital, pondo ênfase no andamento cíclico característico de estruturas industriais que incorporam empresas nacionais, públicas e estrangeiras com poder desigual de acumulação. A partir dessa análise é que se podem compreender de forma integrada os problemas de 'abertura externa' da economia brasileira e de sua articulação 'dependente' do sistema internacional" (Tavares, 1974, p. 130).

Além da nova abordagem teórica para a análise da dinâmica capitalista periférica, Tavares propõe ainda uma nova interpretação para o processo de industrialização no Brasil. Para a autora, o período 1933-1955 pode ser caracterizado como de "industrialização restringida", já que o desenvolvimento de então das forças produtivas resultava insuficiente para implantar o setor de bens de capital, meta que seria atingida apenas posteriormente com a implementação do Plano de Metas a partir de 1956, com a "industrialização propriamente dita". A interpretação anterior do processo de substituição de importações foi reavaliada e a análise dos determinantes do estrangulamento externo e seus efeitos indutores sobre a indus- 
trialização foram considerados menos importantes que a dinâmica endógena de acumulação de capital.

No âmbito desta discussão, Tavares propõe um novo conceito de industrialização, vista não como um mero crescimento industrial, mas, sim, como a instalação de um setor de bens de produção, especialmente bens de capital, que permitiriam internalizar, ao menos em parte, os principais determinantes da dinâmica econômica: o investimento e o progresso técnico.

Assim, para Tavares, quando se trata dos limites da acumulação sob uma perspectiva endógena, deve-se analisar o potencial interno de acumulação e diversificação da estrutura produtiva e como esta se articula com o capital estrangeiro. A tese da autora é, então, a de que os fluxos comerciais e de investimento estrangeiro não determinam de forma exógena a dinâmica da acumulação de capital, mas que "apenas se articulam com ela e modificam-na a partir de dentro, acentuando as mudanças internas em curso na estrutura produtiva e no padrão histórico de acumulação" (Tavares, 1974, p. 132).

A industrialização propriamente dita seria atingida quando a reprodução ampliada do capital torna-se endógena e dominante. Essa etapa de "acumulação especificamente capitalista" (Tavares, 1974, p. 141) nos países periféricos seria compatível com o subdesenvolvimento, bem como com uma maior dependência financeira, tecnológica e política em relação ao capital internacional.

\section{REFERÊNCIAS BIBLIOGRAFICAS}

ADAMS, J. Q. e O'HARA, P. A. (1999) “International political economy”. in O'HARA, P. A., ed. (1999) Encyclopedia of Political Economy. London: Routledge.

BIELSCHOWSKY, R. (1998) "Evolución de las Ideas de la Cepal”. Revista de la Cepal, Número Extraordinario, octubre.

DOW, S. C. (1996) The Methodology of Macroeconomic Thought. Cheltenham: Edward Elgar.

DOW, S. C. (2003) "Babylonian mode of thought". in KING, J. E. (org.) The Elgar Companion to Post Keynesian Economics. Cheltenhan: Edward Elgar.

LUSTIG, N. (1988) "Del estructuralismo al neoestructuralismo: La búsqueda de un paradigma heterodoxo". Estudios CIEPLAN, 23, marzo.

SAAD-FILHO, A. (2005) "The rise and decline of Latin American structuralism and dependency theory”. In JOMO K. S. \& REINERT, E. S., eds. (2005) The Origins of Development Economics. London: Zed Books.

SCHUMPETER, J. A. (1954) History of Economic Analysis. London: Routledge.

TAVARES, M. C. ([1963] 1972) “Auge e declínio do processo de substituição de importações no Brasil”. In TAVARES, M. C. (1972): 27-124.

TAVARES, M. C. (1972) Da Substituição de Importações ao Capitalismo Financeiro. Rio de Janeiro: Zahar, 9a. edição.

TAVARES, M. C. (1974) Acumulação de Capital e Industrialização no Brasil. Tese de Livre-Docência, FEA/UFRJ. Campinas, IE/Unicamp, 3ª . edição (1998).

TAVARES, M. C. (1978) Ciclo e Crise: O Movimento Recente da Industrialização Brasileira. Tese de Professor Titular, FEA/UFRJ. Campinas, IE/Unicamp (1998).

TAVARES, M. C. (1983a) "O movimento geral do capital: Um contraponto à visão da auto-regulação da produção capitalista”, in KONDER, L., CERQUEIRA FILHO, G. \& FIGUEIREDO, E. L., orgs. (1983) Por Que Marx? Rio de Janeiro: Graal, 233-256. 
TAVARES, M. C. (1983b) “Apresentação”. In HOBSON, J. A. ([1916] 1983) A Evolução do Capitalismo Moderno. São Paulo: Abril Cultural, Coleção Os Economistas.

TAVARES, M. C. (1985) “A retomada da hegemonia norte-americana”. Revista de Economia Política, 5 (2), abril-junho. Republicado, em versão ampliada, em TAVARES, M. C. \& FIORI, J. L., orgs. (1997) Poder e Dinheiro. Petrópolis: Vozes.

TAVARES, M. C. (1991) "Economia e felicidade”. Novos Estudos Cebrap, 30, julho.

TAVARES, M. C. (1992) "Ajuste e reestruturação nos países centrais: A modernização conservadora”. Economia e Sociedade, No. 1, agosto. Republicado em TAVARES, M. C. \& FIORI, J. L. (1993) (Des)ajuste Global e Modernização Conservadora. Rio de Janeiro: Paz e Terra.

TAVARES, M. C. (1996) "Entrevista”. in BIDERMAN, C., COZAC, L. F. L., REGO, J. M., orgs. Conversas com Economistas Brasileiros. São Paulo: Editora 34.

TAVARES, M. C. (2000) "Subdesenvolvimento, dominação e luta de classes". In TAVARES, M. C., org. (2000) Celso Furtado e o Brasil. São Paulo: Fundação Perseu Abramo.

TAVARES, M. C. e BELLUZZO, L. G. (1980) “O capital financeiro e a empresa multinacional”. Temas de Ciências Humanas, Vol. 9.

TAVARES, M. C. e BELLUZZO, L. G. (1981) “Ainda a controvérsia sobre a demanda efetiva: uma pequena intervenção”. Revista de Economia Política, 1 (3), julho-setembro.

TAVARES, M. C. e BELLUZZO, L. G. ([1984] 1986) "Uma reflexão sobre a natureza da inflação contemporânea". Revista do Instituto de Economia Industrial, UFRJ, dezembro de 1984. Republicado em: REGO, J. M., org. (1986) Inflação Inercial, Teorias sobre Inflação e o Plano Cruzado. Rio de Janeiro, Paz e Terra.

TAVARES, M. C. e BELLUZZO, L. G. (2004) “A mundialização do capital e a expansão do poder americano". In: FIORI, J. L., org. (2004) O Poder Americano. Petrópolis: Vozes.

TAVARES, M. C. e MELIN, L. E. (1997), "Pós-escrito 1997: A reafirmação da hegemonia norte-americana”. In: TAVARES, M. C. \& FIORI, J. L., orgs. (1997) Poder e Dinheiro. Petrópolis: Vozes.

TAVARES, M. C. e SERRA, J. ([1971] 1972). “Além da estagnação”. El Trimestre Econômico, 152, nov-dez. Republicado em: TAVARES, M. C. (1972): 156-207.

VERNENGO, M. (2006) “Technology, finance, and dependency: Latin American radical political economy in retrospect". Review of Radical Political Economics, 38 (4), Fall. 